\title{
FAKTOR-FAKTOR YANG MEMPENGARUHI PRODUKSI PADA USAHATANI PADI KETAN DI DESA PANYIARAN KECAMATAN CIKAONG KABUPATEN TASIKMALAYA
}

\author{
AFFECTING FACTORS PRODUCTION GLUTINOUS PADDY FARMING IN \\ PANYIARAN VILLAGE CIKALONG DISTRICT TASIKMALAYA REGENCY
}

\author{
HERA HERIYANA $^{{ }^{*}}$, TRISNA INSAN NOOR ${ }^{2}$, AGUS YUNIAWAN ISYANTO ${ }^{1}$ \\ ${ }^{1}$ Fakultas Pertanian, Universitas Galuh \\ ${ }^{2}$ Fakultas Pertanian, Universitas Padjadjaran \\ *E-mail: heraheriyana0@gmail.com.com
}

\begin{abstract}
ABSTRAK
Ketan merupakan salah satu varietas padi yang dapat dijadikan sebagai bahan cadangan alternatif. Biasanya ketan hanya dijadikan sebagai bahan baku pembuatan makanan olahan tradisional sampai skala industri. Kebutuhan beras ketan yang terus meningkat dan penataan input produksi seperti ketersediaan luas lahan yang cenderung menurun, semestinya menjadi pemacu untuk meningkatkan produksi padi ketan. Penelitian ini bertujuan untuk mengetahui pengaruh penggunaan faktor-faktor produksi pada usahatani padi ketan di Desa Panyiaran Kecamatan Cikalong Kabupaten Tasikmalaya. Penelitian dilakukan dengan menggunakan studi kasus pada petani padi di Desa Panyiaran Kecamatan Cikalong Kabupaten Tasikmalaya. Sampel penelitian sebanyak 30 orang yang diambil dengan simple random sampling. Analisis data menggunakan analisis regresi linier berganda. Hasil penelitian menunjukkan secara simultan faktor lahan, benih, pupuk Urea, Pupuk NPK, Pupuk SP-36, pestisida dan tenaga kerja berpengaruh nyata terhadap produksi padi ketan. Secara parsial, lahan, benih, pupuk Urea dan pupuk SP-36 berpengaruh nyata terhadap produksi padi ketan. Variabel pupuk NPK, pestisida, dan tenaga kerja tidak berpengaruh nyata terhadap produksi padi ketan.
\end{abstract}

Kata Kunci : padi ketan, faktor produksi

\begin{abstract}
Sticky rice is a paddy variety that can be used as an alternative as food reserve. Usually sticky rice is only used for making traditional processed foods up to an industrial scale. The need for glutinous rice which continues to increase and the arrangement of production inputs, such as the availability of land area which tends to decline, should be a trigger to increase glutinous rice production. This study aims to determine the effect of the use of production factors on glutinous paddy farming in Panyiaran Village, Cikalong District, Tasikmalaya Regency. The research was conducted using a case study method on paddy farmers in Panyiaran Village, Cikalong District, Tasikmalaya Regency. The research sample was 30 people were taken by simple random sampling. Data analysis using multiple linear regression analysis. The results showed that simultaneously the factors of land, seeds, Urea fertilizer, NPK fertilizer, SP-36 fertilizer, pesticides and labor have a significant effect on glutinous paddy production. While partially the land, seeds, Urea fertilizers and SP-36 fertilizers which have a significant effect glutinous paddy production. NPK fertilizer, pesticides, and labor variables did not significantly affect glutinous paddy production.
\end{abstract}

Keywords: glutinous paddy, production factor

\section{PENDAHULUAN}

Komoditas tanaman pangan yang mempunyai nilai ekonomis cukup tinggi yaitu padi. Padi merupakan produk 


\section{Jurnal Ilmiah Mahasiswa AGROINFO GALUH}

Volume 8, Nomor 1, Januari 2021 : 73-84

pertanian yang menghasilkan beras yang merupakan makanan pokok masyarakat Indonesia. Sebagai bahan pangan pokok, maka ketersediaannya harus selalu ada dan terpenuhi. Pengembangan dan peningkatan produksi padi menjadi isu penting dalam menjaga stabilitas perekonomian nasional.

Ketan merupakan salah satu varietas padi yang dapat dijadikan sebagai bahan cadangan alternatif. Ketan kurang disukai untuk dikonsumsi karena mempunyai tekstur yang lengket. Biasanya ketan hanya dijadikan sebagai bahan baku pembuatan makanan olahan tradisional sampai skala industri.

Konsumsi beras ketan nasional selama lima tahun terakhir (2014-2018) cenderung mengalami kenaikan sebesar $19.10 \%$ pertahun (BPS, 2018). Ketersediaan beras ketan cukup terbatas, sehingga pemenuhan kebutuhan beras ketan harus impor dari Thailand. Sentra produksi ketan di Indonesia terdapat di tiga daerah, yaitu Subang (Jabar), Jawa Tengah, dan Jawa Timur. Data produksi padi ketan sampai saat ini selalu disebut sebagai produksi padi secara keseluruhan. Sehingga data pasti produksi padi ketan secara rinci belum bisa diketahui.

Kemampuan petani dalam memproduksi padi ketan berbeda-beda yang disebabkan oleh karena minimnya pengetahuan petani dalam teknis budidaya padi ketan. Meskipun pada dasarnya, budidaya padi ketan sama saja dengan melakukan budidaya padi varietas lain. Hanya saja jumlah penggunaan faktor produksi yang berbeda.

Kecamatan Cikalong termasuk dalam daerah sentra produksi padi ketan di Kabupaten Tasikmalaya. Jenis padi ketan yang ditanam merupakan varietas padi ketan putih yang menjadi bahan baku umum olahan makanan. Salah satu desa dengan luas tanam padi ketan terbanyak di Kecamatan Cikalong yaitu Desa Panyiaran. Namun produktivitas yang dimiliki cukup rendah. Padahal kebutuhan beras ketan yang terus meningkat dan penataan input produksi seperti ketersediaan luas lahan yang cenderung menurun, semestinya menjadi pemacu untuk meningkatkan produksi padi ketan. Penelitian ini bertujuan untuk mengetahui pengaruh penggunaan faktor-faktor produksi pada usahatani padi ketan di Desa Panyiaran Kecamatan Cikalong Kabupaten Tasikmalaya.

\section{METODE PENELITIAN}

\section{Tempat dan Waktu Penelitian}

Pelaksanaan penelitian ini dilakukan di Desa Panyiaran Kecamatan Cikalong 
Kabupaten Tasikmalaya. Pengambian data dilakukan pada musim tanam AprilSeptember 2020.

\section{Jenis Penelitian}

Penelitian ini merupakan penelitian kuantitatif dengan menggunakan metode studi kasus pada petani padi ketan di Desa Panyiaran.

\section{Variabel Penelitian}

Variabel yang digunakan dalam penelitian ini adalah sebagai berikut :

1. Produksi padi ketan (Y) adalah sejumlah padi ketan yang dihasilkan dalam satu musim tanam, dan dinyatakan dalam satuan kuintal (ku).

2. Luas lahan $\left(\mathrm{X}_{1}\right)$ adalah luas lahan pertanian yang digunakan untuk usahatani padi ketan yang dinyatakan dalam satuan hektar (ha).

3. Benih padi ketan $\left(\mathrm{X}_{2}\right)$ adalah jumlah benih padi ketan yang digunakan petani untuk satu kali musim tanam, dan dinyatakan dalam satuan kilogram (kg).

4. Pupuk Urea $\left(\mathrm{X}_{3}\right)$ adalah jumlah pupuk Urea yang digunakan pada usahatani padi ketan selama satu kali musim tanam, dan dinyatakan dalam satuan kilogram $(\mathrm{kg})$.
5. Pupuk NPK $\left(\mathrm{X}_{4}\right)$ adalah jumlah pupuk NPK yang digunakan pada usahatani padi ketan selama satu kali musim tanam, dan dinyatakan dalam satuan kilogram $(\mathrm{kg})$.

6. Pupuk SP-36 (X) adalah jumlah pupuk SP-36 yang digunakan pada usahatani padi ketan selama satu kali musim tanam, dan dinyatakan dalam satuan kilogram $(\mathrm{kg})$.

7. Pestisida $\left(\mathrm{X}_{6}\right)$ adalah jumlah pestisida yang digunakan pada usahatani padi ketan selama satu kali musim tanam, dan dinyatakan dalam satuan liter (lt).

8. Tenaga kerja $\left(\mathrm{X}_{7}\right)$ adalah jumlah tenaga kerja yang digunakan pada usahatani padi ketan selama satu kali musim tanam, dan dinyatakan dalam satuan hari orang kerja (HOK).

\section{Teknik Penarikan Sampel}

Penarikan sampel dilakukan dengan metode Simple Random Sampling. Pengambilan sampel penelitian menurut Arikunto (2010), jika subjeknya kurang dari 100 orang sebaiknya diambil semuanya, jika subjeknya besar atau lebih dari 100 orang dapat diambil $10-15 \%$ atau 20-25\% atau lebih. Jumlah populasi petani padi ketan di daerah penelitian sebanyak 150 orang. Dari populasi tersebut diambil 
$20 \%$ dari populasi. Sehingga jumlah sampel yang digunakan yaitu $20 \%$ x 150 orang $=30$ orang.

\section{Teknik Pengumpulan Data}

Data primer diperoleh dari petani melalui wawancara langsung dengan menggunakan daftar pertanyaan (kuesioner) yang telah dipersiapkan terlebih dahulu. Data sekunder yang berhubungan dengan penelitian ini diperoleh dari BPP Kecamatan Cikalong dan Kantor Kepala Desa Panyiaran.

\section{Rancangan Analisis Data}

Faktor-faktor yang mempengaruhi produksi padi ketan dianalisis dengan menggunakan analisis regresi linier berganda. Perolehan data yang dikumpulkan selajutnya ditabulasi dan dianalisis sesuai dari tujuan penelitian dengan menggunakan analisis regresi linear berganda menurut Kurniawan (2016) dengan model matematisnya sebagai berikut:

$$
\begin{gathered}
\mathrm{Y}=\beta_{0+} \beta_{1} X_{1+} \beta_{2} X_{2}+\beta_{3} X_{3+} \beta_{4} X_{4}+\beta_{5} X_{5}+ \\
\beta_{6} X_{6}+\beta_{7} X_{7}+\mathrm{e}
\end{gathered}
$$

Dimana:

$\mathrm{Y} \quad$ : Produksi padi ketan $(\mathrm{ku})$

$\beta_{0} \quad$ : Intersep atau konstanta

$\beta_{1,2,3,4,5}$ : Koefisien regresi

$X_{1} \quad$ : Luas lahan (ha)

$$
\begin{array}{ll}
X_{2} & : \text { Benih }(\mathrm{kg}) \\
X_{3} & : \text { Pupuk Urea }(\mathrm{kg}) \\
X_{4} & : \text { Pupuk NPK }(\mathrm{kg}) \\
X_{5} & : \text { Pupuk SP-36 }(\mathrm{kg}) \\
X_{6} & : \text { Pestisida (lt) } \\
X_{7} & : \text { Tenaga kerja (HOK) }
\end{array}
$$

\section{Uji Asumsi Klasik}

\section{Uji Normalitas}

Pengujian normalitas dilakukan secara visual dengan metode grafik normal probability plots dalam program SPSS.

\section{Uji Multikorlinieritas}

Pengujia Multikolineritas dengan menggunakan Variace Inflation Factor (VIF) dengan rumus berikut:

$$
V I F=\frac{1}{1-R i^{2}}
$$

$\mathrm{Ri}^{2}$ merupakan koefisien determinasi yang diperoleh dengan meregresikan salah satu variabel bebas $\mathrm{X}_{1}$ terhadap variabel bebas lainnya. Jika nilai VIF kurang atau sama dengan 10 (Gujarati, 2003) maka diantara variabel independen tidak terdapat multikolinieritas.

\section{Uji Heteroskodastisitas}

Untuk menguji ada tidaknya heteroskodastisitas digunakan Glajser, yaitu dengan mengkorelasikan variable independen variabel independen terhadap nilai absolut dari residual (error). Jika nilai koefisien korelasi antara variable bebas 
dengan nilai absolut dari residual (error) signifikan, maka kesimpulannya terdapat heteroskodastisitas (varian dari residual tidak homogen).

\section{Karaktersitik Responden}

Karakteristik responden dalam penelitian ini terdiri dari umur, tingkat pendidikan, jumlah tanggungan keluarga, dan penguasaan lahan.

\section{HASIL DAN PEMBAHASAN}

\section{Tabel 1. Karaktersitik Responden}

\begin{tabular}{|c|c|c|c|}
\hline No & Uraian & Jumlah Petani (orang) & Pesrsentase (\%) \\
\hline \multirow[t]{4}{*}{1} & Umur (tahun) & & \\
\hline & Produktif (15-64) & 18 & 60.00 \\
\hline & Sudah tidak produktif $(\geq 65)$ & 12 & 40.00 \\
\hline & Jumlah & 30 & 100.00 \\
\hline \multirow[t]{6}{*}{2} & Pendidikan Formal & & \\
\hline & SD & 14 & 46.67 \\
\hline & SMP & 9 & 30.0 \\
\hline & SMA & 6 & 20.00 \\
\hline & D3/S1 & 1 & 3.33 \\
\hline & Jumlah & 30 & 100.00 \\
\hline \multirow[t]{4}{*}{3} & Tanggungan Keluarga (orang) & & \\
\hline & $\operatorname{Kecil}(<5)$ & 30 & 100.00 \\
\hline & Besar $(\geq 5)$ & - & \\
\hline & Jumlah & 30 & 100.00 \\
\hline \multirow[t]{5}{*}{4} & Penguasaan Lahan (hektar) & & \\
\hline & $\operatorname{Kecil}(<0.5)$ & 30 & 100.00 \\
\hline & Menengah $(0.5-1)$ & 0 & - \\
\hline & Luas $(>1)$ & 0 & - \\
\hline & Jumlah & 30 & 100.00 \\
\hline
\end{tabular}

Sumber : Hasil olah data primer, 2020. umur petani termuda yaitu 43 tahun dan

Umur yang dimiliki petani dapat berpengaruh terhadap penyerapan dan pengambilan keputusan dalam penerapan teknologi dan inovasi baru pada kegiatan usahataninya. Hal ini karena umur dapat dijadikan sebagai indikator produktif atau tidaknya seseorang dalam mengelola usahanya. Manusia dikatakan produktif apabila memiliki usia 15-64 tahun (Nurhasikin dalam Dewi dkk, 2018). Petani responden di Desa Panyiaran dominan berada pada usia produktif atau berada pada usia 15-44 tahun. Tingkat umur tertua 75 tahun.

Pendidikan sangat menentukan tingkat kompetensi petani dalam melakukan kegiatan pertanian (Manyamsari \& Mujiburrahmad 2014). Kompetensi tersebut berhubungan dengan pengelolaan usahatani yang dilakukan untuk mencapai tujuan yang direncanakan. Petani responden di Desa Panyiaran didominasi oleh lulusan Sekolah Dasar. Rata-rata pendidikan yang ditempuh petani responden yaitu 8 tahun. 
Tanggungan keluarga yang dimiliki petani dapat berpengaruh terhadap peningkatan produksi usahatani. Petani dengan jumlah tanggungan keluarga yang besar dituntut untuk lebih meningkatkan produksi usahataninya yang diharapkan dapat memenuhi kebutuhan sehari-harinya. Jumlah tanggungan menurut Ahmadi dalam Hanum (2018) dapat digolongkan menjadi dua, yaitu tanggungan besar apabila jumlah tanggungan $\geq 5$ orang, dan tanggungan kecil apabila jumlah tanggungan $<5$ orang. Petani responden di Desa Panyiaran berada pada kategori kecil. Rata-rata jumlah tanggungan keluarga petani responden sebanyak 2 orang.

Luas lahan yang digunakan petani dalam berusahatani dapat berpengaruh terhadap jumlah penggunaan faktor input produksi. Sayogyo dalam Susilowati dan Maulana (2012) mengelompokkan petani di Jawa ke dalam tiga kategori, yaitu: petani skala kecil dengan luas lahan usahatani $<0,5$ ha, skala menengah dengan luas lahan usahatani 0,5-1,0 ha, dan skala luas dengan luas lahan usahatani >1,0 ha. Penguasaan lahan petani responden di Desa Panyiaran secara keseluruhan berada pada kategori kecil $(<0.5)$ dengan rata-rata penguasaan lahan petani responden yaitu 0.02 hektar.

\section{Uji Asumsi Klasik}

\section{Uji Normalitas}

Uji normalitas dilakukan untuk menguji distribusi setiap nilai variabel bebas tertentu berdistribusi normal atau tidak dalam model regresi linear. Pengujian normalitas dilakukan secara visual dengan metode grafik normal probability plots dalam program SPSS.

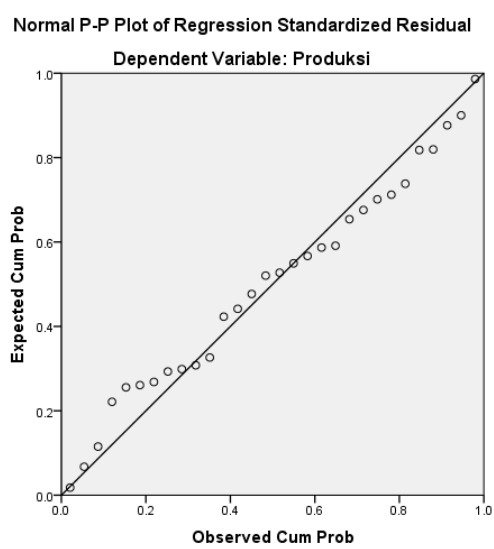

Gambar 3. Normal P-P Plot of Regression Standardized Residual

Hasil analisis menunjukkan data menyebar di sekitar garis diagonal dan mengikuti arah garis diagonal, maka dapat disimpulkan bahwa regresi memenuhi asumsi normalitas.

\section{Uji Multikoliniearitas}

Multikorelasional merupakan keadaan dimana beberapa atau semua variabel independen dalam model saling berkorelasi tinggi. 
Tabel 2. Hasil Nilai Variance Inflation

\begin{tabular}{lcc}
\multicolumn{3}{c}{ Factor } \\
\multicolumn{1}{c}{ Model } & Tolerance & \multicolumn{1}{c}{ VIF } \\
\hline (Constant) & & \\
Lahan & 0.127 & 7.882 \\
Benih & 0.143 & 6.975 \\
Urea & 0.104 & 9.659 \\
NPK & 0.146 & 6.851 \\
SP-36 & 0.369 & 2.707 \\
Pestisida & 0.330 & 3.026 \\
Tenaga Kerja & 0.446 & 2.241 \\
\hline Sumber : Hasil olah data primer, 2020
\end{tabular}

Hasil analisis menunjukkan bahwa nilai VIF pada setiap variabel kurang 10.

Maka disimpulkan bahwa diantara variabel independen

tidak

terdapat multikolinieritas.

\section{Uji Heteroskedastisitas}

Pengujian heteroskodastisitas dilakukan dengan uji Glajser yang mengkorelasikan variable independen terhadap nilai absolut dari residual (error).

Tabel 3. Hasil Uji Glasjer

\begin{tabular}{|c|c|c|c|c|c|c|}
\hline & \multirow[b]{2}{*}{ Model } & \multicolumn{2}{|c|}{$\begin{array}{l}\text { Unstandardized } \\
\text { Coefiennts }\end{array}$} & $\begin{array}{c}\text { Standardized } \\
\text { Coefiennts } \\
\end{array}$ & \multirow[b]{2}{*}{$\mathrm{t}$} & \multirow[b]{2}{*}{ Sig. } \\
\hline & & B & Std. Error & Beta & & \\
\hline \multirow[t]{8}{*}{1} & (Constant) & $3.997 \mathrm{E}-16$ & .068 & & .000 & 1.000 \\
\hline & Lahan & .000 & 6.259 & .000 & .000 & 1.000 \\
\hline & Benih & .000 & .211 & .000 & .000 & 1.000 \\
\hline & Urea & .000 & .023 & .000 & .000 & 1.000 \\
\hline & NPK & .000 & .022 & .000 & .000 & 1.000 \\
\hline & $\mathrm{SP}$ & .000 & .039 & .000 & .000 & 1.000 \\
\hline & Pestisida & .000 & 2.452 & .000 & .000 & 1.000 \\
\hline & TK & .000 & .047 & .000 & .000 & 1.000 \\
\hline
\end{tabular}

Sumber : Hasil olah data primer, 2020.

Hasil uji Glasjer menunjukkan bahwa nilai koefisien korelasi masingmasing variable bebas dengan nilai absolut dari residual (error) tidak signifikan. Sehingga dapat disimpulkan tidak terdapat gejala heteroskodastisitas (varian dari residual tidak homogen).

\section{Analisis Faktor yang Berpengaruh Terhadap Produksi Padi Ketan}

Faktor-faktor yang mempengaruhi terhadap produksi padi ketan di Desa
Panyiaran Kecamatan Cikalong dianalisis dengan menggunakan model regresi linear berganda. Analisis regresi dilakukan untuk mengetahui pengaruh dari variabel yang diteliti terhadap produksi padi ketan. Variabel produksi tersebut yaitu lahan, benih, pupuk urea, pupuk NPK, pupuk SP36 , pestisida dan tenaga kerja.

\section{Uji Parsial (Uji t)}

Uji parsial digunakan untuk mengetahui pengaruh variabel penelitian luas lahan, benih, pupuk urea, pupuk NPK, pupuk SP-36, pestisida, dan tenaga kerja berpengaruh nyata secara parsial terhadap 
produksi padi ketan. Kriteria pengambilan keputusan berdasarkan perbandingan thitung dengan nilai pada t-tabel pada tingkat kesalahan 0.05 uji dua pihak dan $d b$ $=n-\mathrm{k}$. Jika t-hitung $>$ t-tabel pada $\alpha=$ 5\%, maka $\mathrm{H}_{0}$ ditolak dan $\mathrm{H}_{1}$ diterima atau variabel berpengaruh signifikan.

Tabel 4. Hasil Analisis Rergresi Linear Berganda

\begin{tabular}{llrrrrr}
\hline \multirow{2}{*}{ Model } & \multicolumn{2}{c}{ Unstandardized Coefficients } & \multicolumn{2}{c}{$\begin{array}{c}\text { Standardized } \\
\text { Coefficients }\end{array}$} & \multirow{2}{*}{ S } & \multicolumn{2}{c}{ Sig. } \\
\cline { 2 - 5 } & \multicolumn{1}{c}{ B } & \multicolumn{1}{c}{ Std. Error } & Beta & & .019 \\
\hline 1 & (Constant) & -0.171 & .068 & .375 & 2.840 & $.010^{*}$ \\
& Lahan & 17.774 & 6.259 & .383 & 3.084 & $.005^{*}$ \\
Benih & .652 & .211 & .388 & 2.658 & $.014^{*}$ \\
Urea & .061 & .023 & .205 & 1.670 & .109 \\
NPK & .037 & .022 & -.500 & -6.464 & $.000^{*}$ \\
SP-36 & -.255 & .039 & .088 & 1.073 & .295 \\
Pestisida & 2.630 & 2.452 & -.095 & -1.350 & .191 \\
\hline
\end{tabular}

Sumber : Hasil olah data primer, 2020.

Keterangan : nyata pada $* \alpha=0.05$

Tabel 4 menunjukkan bahwa faktor lahan, benih, pupuk urea, dan pupuk SP36 berpengaruh terhadap produksi padi ketan. Hal ini terlihat dari nilai t-hitung variabel lahan, benih, pupuk urea, dan pupuk SP-36 lebih besar dari nilai ttabel $_{(22 ; 0.05)}$ yaitu 2.0738 dan signifikan pada $\alpha=0.05$. Variabel pupuk NPK, pestisida dan tenaga kerja tidak berpengaruh nyata terhadap produksi padi ketan. Nilai t-hitung variabel pupuk NPK, pestisida dan tenaga kerja lebih kecil dari nilai t-tabel yaitu 2.0738 pada $\alpha=0.05$. Model persamaan fungsi matematis dari faktor yang mempengaruhi produksi padi ketan dapat ditulis sebagai berikut :

$$
\begin{gathered}
\mathrm{Y}=-0.171+17.774 X_{1}+0.652 X_{2}+0.061 X_{3} \\
+0.037 X_{4}-0.255 X_{5}+2.630 X_{6}-0.063 X_{7} \\
+\mathrm{e}
\end{gathered}
$$

Nilai koefisien kostanta sebesar 0.171 yang berarti jika variabel faktor penduga sama dengan nol maka produksi akan menurun 0.171 satuan. Atau dapat dikatakan produksi nol. Nilai koefisien variabel lahan sebesar 17.774 dan berpengaruh nyata pada $\alpha=0.05$ terhadap produksi padi ketan. Nilai t-hitung variabel lahan sebesar 2.840 lebih besar dari t-tabel 2.0738. Nilai elastisitas lahan sebesar 17.774 dan bernilai positif menunjukkan adanya hubungan searah antara lahan dengan produksi padi ketan. Jika luas lahan ditambah sebanyak $1 \%$, maka produksi padi ketan akan bertambah sebanyak $17.774 \%$ dengan asumsi variabel lain dianggap tetap. Hal ini sejalan dengan penelitian Manggala dan Rocminarni (2018) yang menyatakan bahwa luas lahan sawah memiliki pengaruh positif dan 


\section{Jurnal Ilmiah Mahasiswa AGROINFO GALUH \\ Volume 8, Nomor 1, Januari 2021 : 73-84}

signifikan terhadap produksi padi. Penggunaan lahan untuk padi ketan tidak seluas untuk padi varietas lainnya. Karena padi ketan bukan merupakan konsumsi utama masyarakat Desa Panyiaran. Ratarata penggunaan lahan sawah untuk tanaman padi ketan yaitu 0.02 ha.

Nilai koefisien variabel benih sebesar 0.652 dan berpengaruh nyata pada $\alpha=0.05$ terhadap produksi padi ketan. Nilai t-hitung variabel benih sebesar 3.084 lebih besar dari t-tabel 2.0738. Nilai elastisitas benih sebesar 0.652 dan bernilai positif menunjukkan adanya hubungan searah antara benih dengan produksi padi ketan. Jika penggunaan benih ditambah sebanyak 1\%, maka produksi padi ketan akan bertambah sebanyak $0.652 \%$ dengan asumsi variabel lain dianggap tetap. Hal ini sejalan dengan penelitian Onibala, dkk (2018) yang menyatakan bahwa jumlah penggunaan benih berpengaruh terhadap produksi padi. Penggunaan benih petani responden ratarata sebanyak $26.6 \mathrm{~kg} / \mathrm{ha}$. Selain itu benih yang digunakan merupakan benih hasil panen sendiri.

Nilai koefisien variabel pupuk urea sebesar 0.061 dan berpengaruh nyata pada $\alpha=0.05$ terhadap produksi padi ketan. Nilai t-hitung variabel pupuk urea sebesar 2.658 lebih besar dari t-tabel 2.0738. Nilai elastisitas pupuk urea sebesar 0.061 dan bernilai positif menunjukkan adanya hubungan searah antara pupuk urea dengan produksi padi ketan. Jika penggunaan pupuk urea ditambah sebanyak $1 \%$, maka produksi padi ketan akan bertambah sebanyak $0.061 \%$ dengan asumsi variabel lain dianggap tetap. Hal ini sejalan dengan penelitian Onibala, dkk (2018) yang menyatakan bahwa jumlah penggunaan urea berpengaruh terhadap produksi padi. Penggunaan pupuk urea petani responden rata-rata sebanyak 252 $\mathrm{kg} / \mathrm{ha}$.

Nilai koefisien variabel pupuk NPK sebesar 0.037 dan tidak berpengaruh nyata terhadap produksi padi ketan. Nilai thitung variabel pupuk NPK sebesar 1.670 lebih kecil dari t-tabel 2.0738. Penggunaan pupuk NPK petani responden rata-rata sebanyak $209 \mathrm{~kg} /$ ha.

Nilai koefisien variabel pupuk SP36 sebesar -0.255 dan berpengaruh nyata pada $\alpha=0.05$ terhadap produksi padi ketan. Nilai t-hitung variabel pupuk SP-36 sebesar 6.464 lebih besar dari t-tabel 2.0738. Nilai elastisitas pupuk SP-36 sebesar 0.255 dan bernilai negatif menunjukkan adanya hubungan terbalik antara pupuk SP-36 dengan produksi padi ketan. Jika penggunaan pupuk SP-36 ditambah sebanyak 1\%, maka produksi 
padi ketan akan menurun sebanyak $0.255 \%$ dengan asumsi variabel lain dianggap tetap. Nilai koefisien pupuk SP-36 bernilai negatif menunjukkan bahwa penggunaan pupupk SP-36 oleh petani sudah berlebih. Rata-rata penggunaan pupuk SP-36 oleh petani sebanyak $77 \mathrm{~kg} / \mathrm{ha}$.

Nilai koefisien variabel pestisida sebesar 2.630 dan tidak berpengaruh nyata pada $\alpha=0.05$ terhadap produksi padi ketan. Nilai t-hitung variabel pestisida sebesar 1.073 lebih kecil dari t-tabel 2.0738. Rata-rata penggunaan pestisida oleh petani sebanyak 1.5 liter/ha. Pestisida tidak berpengaruh nyata terhadap produksi padi ketan karena didaerah penelitian tingkat serangan hama dan penyakit pada padi ketan masih dibawah ambang batas ekonomis.
Nilai koefisien variabel tenaga kerja sebesar -0.063 dan tidak berpengaruh nyata pada $\alpha=0.05$ terhadap produksi padi ketan. Nilai t-hitung variabel tenaga kerja sebesar -1.350 lebih kecil dari t-tabel 2.0738. Rata-rata penggunaan pestisida oleh petani sebanyak $75 \mathrm{HOK} / \mathrm{ha}$.

\section{Uji Simultan (Uji F)}

Uji simultan dilakukan untuk mengetahui pengaruh variabel penelitian secara bersama-sama terhadap produksi padi ketan. Pengujian dilakukan dengan membandingkan nilai $\mathrm{P}$ value $(\mathrm{sig})<\alpha$ maka $\mathrm{H}_{0}$ ditolak dan $\mathrm{H}_{1}$ diterima, atau variabel lahan, benih, pupuk urea, pupuk NPK, pupuk SP-36, pestisida dan tenaga kerja secara bersama-sama berpengaruh terhadap produksi padi ketan.

Tabel 5. Analisis of Varian

\begin{tabular}{|c|c|c|c|c|c|c|}
\hline \multicolumn{7}{|c|}{$\mathrm{ANOVA}^{\mathrm{a}}$} \\
\hline & Model & $\begin{array}{l}\text { Sum of } \\
\text { Squares }\end{array}$ & $\mathrm{df}$ & Mean Square & $\mathrm{F}$ & Sig. \\
\hline \multirow[t]{3}{*}{1} & Regression & 5.849 & 7 & 0.836 & 61.601 & $.000^{\mathrm{b}}$ \\
\hline & Residual & 0.298 & 22 & 0.14 & & \\
\hline & Total & 6.147 & 29 & & & \\
\hline
\end{tabular}

Sumber : Hasil olah data primer, 2020.

Tabel 12 menunjukkan bahwa secara simultan variabel lahan, benih, pupuk urea, pupuk NPK, pupuk SP-36, pestisida dan tenaga kerja berpengaruh nyata dan signifikan terhadap produksi padi ketan. Hal ini terlihat dari Nilai nilai $\mathrm{P}$ value $(0.000)<\alpha(0.05)$. Nilai probabilitas sebesar 61.601 berarti bahwa peningkatan penggunaan faktor produksi sebanyak $1 \%$ secara bersama-sama akan meningkatkan produksi padi ketan sebesar $61.60 \%$

\section{Koefisien Determinasi $\left(\mathbf{R}^{2}\right)$}

Nilai koefisien determinasi digunakan untuk mengukur besaran sumbangan variabel penelitian yang digunakan terhadap produksi padi ketan. 
Tabel 6. Nilai Koefisien Determinasi

\begin{tabular}{ccccc}
\hline Model & R & R Square & Adjusted R Square & Std. Error of the Estimate \\
\hline 1 & $.975^{\text {a }}$ & .951 & .936 & 0.11646 \\
\hline
\end{tabular}

b. Dependent Variable: Produksi

Nilai koefisien determinasi $\left(\mathrm{R}^{2}\right)$ sebesar 0,936. Hal tersebut berarti 93,6\% produksi padi ketan dapat dijelaskan oleh variabel yang digunakan dalam penelitian. Sedangkan $6,4 \%$ sisanya dipengaruhi oleh variabel lain yang tidak dimasukkan ke dalam model penelitian.

\section{KESIMPULAN DAN SARAN}

\section{Kesimpulan}

Berdasarkan hasil penelitian yang telah dilakukan, maka dapat disimpulkan secara simultan faktor lahan, benih, pupuk Urea, Pupuk NPK, Pupuk SP-36, pestisida dan tenaga kerja berpengaruh nyata terhadap produksi padi ketan. Secara parsial, lahan, benih, pupuk urea dan pupuk SP-36 berpengaruh nyata terhadap produksi padi ketan; sedangkan pupuk NPK, pestisida, dan tenaga kerja tidak berpengaruh nyata terhadap produksi padi ketan.

\section{Saran}

Penggunaan pupuk pada usahatani padi ketan hendaknya diberikan sesuai dengan dosis yang dianjurkan atau sesuai dengan kebutuhan tanaman padi ketan terutama pada penggunaan pupupk SP-36 yang jumlahnya harus dikurangi. Peningkatan produksi padi ketan dapat dilakukan dengan penggunaan benih unggul serta penambahan areal lahan untuk tanam padi ketan.

\section{DAFTAR PUSTAKA}

Arikunto, S. 2010. Prosedur Penelitian Suatu Pendekatan Praktik. Jakarta: Rineka Cipta.

Badan Pusat Statistik. 2018. Statistik Konsumsi Pangan Tahun 2018. Jakarta: BPS.

Dewi, I.N., Awang, S.A., Andayani, W. dan Suryanto, P. 2018. Karakteristik Petani dan Kontribusi Hutan Kemasyarakatan (HKm) Terhadap Pendapatan Petani di Kulon Progo. Jurnal Ilmu Kehutanan, 12 : 86-98.

Gujarati, D. 2003. Ekonometri Dasar. Terjemahan: Sumarno Zain. Jakarta: Erlangga

Hanum, N. 2018. Pengaruh Pendapatan, Jumlah Tanggungan Keluarga Dan Pendidikan Terhadap Pola Konsumsi Rumah Tangga Nelayan Di Desa Seuneubok Rambong Aceh Timur. Jurnal Samudra Ekonomika, 2(1) : 13-18.

Manggala, R.B. dan Rochminarni, A.B. 2018. Faktor-faktor yang Mempengaruhi Produksi Padi di Desa Sumengko Kecamatan Sukomoro Kabupaten Nganjuk. Jurnal Ilmu Ekonomi, 2(3): 441-452. Manyamsari, I. dan Mujiburrahmad. 2014. Karakteristik petani dan 


\section{Jurnal Ilmiah Mahasiswa AGROINFO GALUH}

Volume 8, Nomor 1, Januari 2021 : 73-84

hubungannya dengan kompetensi petani lahan sempit. Agrisep 15(2): 58-74.

Onibala, A.G., Sondakh, M.L., Kaunang, R. dan Mandei, J. Analisis FaktorFaktor yang Mempengaruhi Produksi Padi Sawah di Kelurahan Koya Kecamatan Tondano Selatan.
Agri-Sosio Ekonomi, 13(2A) : 237 242237

Susilowati, S.H. dan Maulana, M. 2012.

Luas Lahan Usahatani dan Kesejahteraan Petani : Eksistensi Petani Gurem dan Urgensi Kebijakan Reforma Agraria. Analisis Kebijakan Pertanian, 10 (1) : 17-30. 